\title{
Performance analysis of variable speed multiphase induction motor with pole phase modulation
}

\author{
HuiJuan LiU，Jun Wang，Zhenyang Zhang \\ School of Electrical Engineering, Beijing Jiaotong University \\ 3 Shangyuan Cun, Haidian District, Beijing \\ e-mail:hjliu@bjtu.edu.cn
}

(Received: 22.04.2015, revised: 25.02.2016)

\begin{abstract}
The pole phase modulation (PPM) technique is an effective method to extend speed range and torque capabilities for an integrated starter and hybrid electric vehicles applications. In this paper, the five pole-phase combination types of a multiphase induction motor (IM) with 36 stator slots and 36 stator conductors are presented and compared quantitatively by using the time-stepping finite element method (TS-FEM). The 36 stator conductors of the proposed multiphase IM are fed by a 36 leg inverter and the current phase angle and amplitude of each stator conductor can be controlled independently. This paper focuses on the winding connection, the PPM technique and the performance comparative analysis of each pole-phase combination types of the proposed multiphase IM. The flux distribution, air-gap flux density, output torque, core losses and efficiency of five pole-phase combination types have been investigated.
\end{abstract}

Key words: induction motor (IM), pole phase modulation (PPM), efficiency, FEM

\section{Introduction}

Multiphase induction motors (IMs) have more advantages than a conventional three-phase IM [1]. Owing to reducing the slot harmonics, multiphase IM can achieve high efficiency [2]. And the fault tolerant capability of multiphase IM is an important advantage.

Multiphase IM driving system was usually applied in the conventional scalar control in earlier years [3]. In 1957, G.H. Rawcliffe and R.F. Burbidge proposed a 2:1 pole-changing IM [4]. Pole amplitude modulation (PAM) is the efficient continuous pole changing technique without the need to use mechanical switches. A special winding arrangement must be designed for PAM to change the pole number of the multiphase IM. According to the clock diagram method to reverse the current phase of some coils, the pole number of the windings can be changed [5-7].

Pole phase modulation (PPM) is one of the techniques for speed and torque controlling of a multiphase IM without causing power failure. Effective torque control technology deployed during the pole-changing transition of a 3:1 pole IM was recently proposed by John W. Kelly and Elias G. Strangas [8]. In reference [9], the winding design strategy using the PPM method was presented, and the performance of a multiphase induction machine with a 1:3 speed ratio 
was comparatively studied. In [10], a 15-phase induction motor driven with a 1:3:5 speed ratio using PPM is designed.

By using PPM, the power of an electrical machine can change pole pairs without a power cut, while the method of using a change of supply sequence does not perform well. Since the machine using PPM is applied to a ship's propulsion, electrical traction, electric aircraft applications and some large power equipment, the method of PPM is more suited for driving system applications than the use of change of supply sequence.

In this paper, five pole-phase combination types of a multiphase induction motor (IM) which has 36 stator slots and 36 stator conductors are presented. The 36 stator conductors of the proposed multiphase IM are fed by a 36 leg inverter and the current phase angle and amplitude of each stator conductor can be controlled independently. The multiphase induction motor can be operated with 1:2:3:6:9 speed ratios for PPM, such as 18 phase 2 pole, 9 phase 4 pole, 6 phase 6 pole, 3 phase 12 pole and 2 phase 18 pole. The winding connection, the PPM technique and the performance comparative analysis of each pole-phase combination types of the proposed multiphase IM are compared quantitatively by using time-stepping finite element method (TS-FEM). The flux distribution, air-gap flux density, output torque, core losses and efficiency of five pole-phase combination types have been investigated.

\section{Winding arrangements of proposed IM}

As shown in Fig. 1, the novel multiphase IM has one rotor and one stator, and the structures of them are the same as that of a conventional one. According to some design principles of induction machines, the stator slots and rotor slots are cautiously chosen. By try-and-error the air gap length is determined to ensure the high power factor of the IM. The main dimensions of the novel multiphase IM are shown in Table 1.

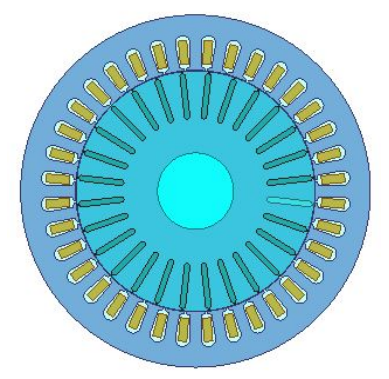

Fig. 1. The cross-section of the multiphase IM

In the novel multiphase IM, each stator conductor forms part of a single phase of the machine, therefore, the proposed multiphase IM has a total of 36 phases. The 36 stator conductors are fed by a 36 leg inverter as shown in Fig. 2. And the current phase angle and amplitude of each conductor can be controlled independently. By redesigning the stator windings, the novel multiphase IM can be operated in many kinds of pole phase combination to extend speed range and torque capabilities. 
Table 1. Main dimensions

\begin{tabular}{l|c}
\hline Stator outer dimension $(\mathrm{mm})$ & 175 \\
\hline Stator inner dimension $(\mathrm{mm})$ & 120 \\
\hline Cage rotor outer dimension $(\mathrm{mm})$ & 119.4 \\
\hline Cage rotor inner dimension $(\mathrm{mm})$ & 38 \\
\hline Stator slot number & 36 \\
\hline Rotor slot number & 28 \\
\hline Stack length $(\mathrm{mm})$ & 110 \\
\hline Winding layer & 1 \\
\hline
\end{tabular}

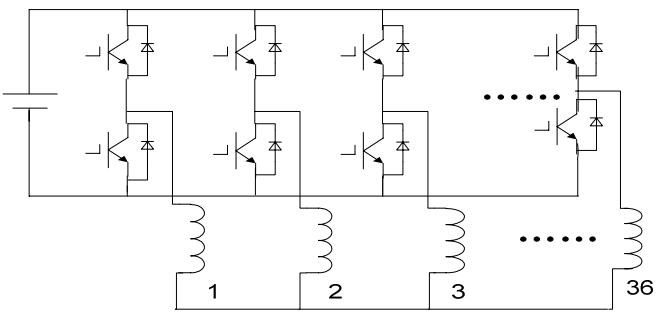

Fig. 2. Power converter and 36 stator slot conductor

As shown in Fig. 2, we can control the conduction angle of the IGBT in each leg to change the current phase angle of each stator conductor. So the novel multiphase IM can operate at different rotating magnetic fields. It can accomplish five different pole phase operations. Usually, for an electrical machine, there are two methods to define the phase number of the machine; the first method is that the phase number is equal to the number of phase belt; the other one is that the phase number is equal to the half of phase belt. In our proposed machine, we use the second definition, and then the phase number is the half of phase belt.

In order to obtain a symmetrical rotating magnetic field, the machine should be excited by symmetrical multiphase currents whose phase number should be equal to the number of phase belt. Therefore the proposed multiphase IM should be excited by the multiphase currents whose phase number is equal to the double phase number of the machine. For example, the proposed five different pole phase IM should be fed by the multiphase currents with the following phase numbers, such as 36 phases for 18 phase 2 pole IM, 18 phases for 9 phase 4 pole IM, 12 phases for 6 phase 6 pole IM, 6 phases for 3 phase 12 pole IM and 4 phases for 2 phase 18 pole IM respectively.

Tables 2 to 6 clearly show the PPM of the novel multiphase IM. Details of each slot angle and the current direction of each conductor are shown there. In the novel multiphase IM, slot angle and the current phase angle in the same stator slot are uniform. In spite of some different slots belonging to the same phase, these different slots should be energized respectively. In Table 2, the alphabet a-r represents the 18 phase currents with phase difference of 10 electrical degrees. In Table 3, the alphabet a-i represents the 9 phase currents with phase difference of 20 electrical degrees. In Table 4, the alphabet a-f represents the 6 phase currents with phase difference of 30 electrical degrees. In Table 5, a, b and c represents the 3 phase currents with phase difference of 60 electrical degrees. In Table 6 , a and $b$ represent the 2 phase currents with phase angle difference of 90 electrical degrees. 
Table 2. Conductor current for 18-phase with 2-pole

\begin{tabular}{|c|c|c|c|c|c|c|c|c|c|c|c|c|c|c|c|c|c|c|}
\hline Slot No. & 1 & 2 & 3 & 4 & 5 & 6 & 7 & 8 & 9 & 10 & 11 & 12 & 13 & 14 & 15 & 16 & 17 & 18 \\
\hline $\begin{array}{c}\text { Electrical } \\
\text { angle }\end{array}$ & 0 & 10 & 20 & 30 & 40 & 50 & 60 & 70 & 80 & 90 & 100 & 110 & 120 & 130 & 140 & 150 & 160 & 170 \\
\hline Conductor & + & + & + & + & + & + & + & + & + & + & + & + & + & + & + & + & + & + \\
\hline $\begin{array}{l}\text { Phase } \\
\text { current }\end{array}$ & $\mathrm{a}$ & b & $\mathrm{c}$ & $\mathrm{d}$ & $\mathrm{e}$ & $f$ & g & $\mathrm{h}$ & $\mathrm{i}$ & $\mathrm{j}$ & $\mathrm{k}$ & 1 & $\mathrm{~m}$ & $\mathrm{n}$ & o & $\mathrm{p}$ & $\mathrm{q}$ & $\mathrm{r}$ \\
\hline Poles & \multicolumn{18}{|c|}{$\mathbf{N}$} \\
\hline Slot No. & 19 & 20 & 21 & 22 & 23 & 24 & 25 & 26 & 27 & 28 & 29 & 30 & 31 & 32 & 33 & 34 & 35 & 36 \\
\hline $\begin{array}{c}\text { Electrical } \\
\text { angle }\end{array}$ & 180 & 190 & 200 & 210 & 220 & 230 & 240 & 250 & 260 & 270 & 280 & 290 & 300 & 310 & 320 & 330 & 340 & 350 \\
\hline Conductor & - & - & - & - & - & - & - & - & - & - & - & - & - & - & - & - & - & - \\
\hline $\begin{array}{l}\text { Phase } \\
\text { current }\end{array}$ & $-\mathrm{a}$ & $-b$ & $-\mathrm{c}$ & $-\mathrm{d}$ & $-\mathrm{e}$ & $-f$ & $-\mathrm{g}$ & $-\mathrm{h}$ & $-\mathrm{i}$ & $-\mathrm{j}$ & $-\mathrm{k}$ & -1 & $-\mathrm{m}$ & $-\mathrm{n}$ & -0 & $-p$ & $-\mathrm{q}$ & $-r$ \\
\hline Poles & \\
\hline
\end{tabular}

Table 3. Conductor current for 9 phases with 4 poles

\begin{tabular}{|c|c|c|c|c|c|c|c|c|c|c|c|c|c|c|c|c|c|c|}
\hline Slot No. & 1 & 2 & 3 & 4 & 5 & 6 & 7 & 8 & 9 & 10 & 11 & 12 & 13 & 14 & 15 & 16 & 17 & 18 \\
\hline $\begin{array}{c}\text { Electrical } \\
\text { angle }\end{array}$ & 0 & 20 & 40 & 60 & 80 & 100 & 120 & 140 & 160 & 180 & 200 & 220 & 240 & 260 & 280 & 300 & 320 & 340 \\
\hline Conductor & + & + & + & + & + & + & + & + & + & - & - & - & - & - & - & - & - & - \\
\hline $\begin{array}{l}\text { Phase } \\
\text { current }\end{array}$ & $\mathrm{a}$ & $\mathrm{b}$ & $\mathrm{c}$ & $\mathrm{d}$ & $\mathrm{e}$ & $\mathrm{f}$ & $\mathrm{g}$ & h & $\mathrm{i}$ & $-\mathrm{a}$ & $-b$ & $-\mathrm{c}$ & $-\mathrm{d}$ & $-\mathrm{e}$ & $-\mathrm{f}$ & $-\mathrm{g}$ & $-\mathrm{h}$ & $-\mathrm{i}$ \\
\hline Poles & \multicolumn{9}{|c|}{$\mathbf{N}$} & \multicolumn{9}{|c|}{$\mathbf{S}$} \\
\hline Slot No. & 19 & 20 & 21 & 22 & 23 & 24 & 25 & 26 & 27 & 28 & 29 & 30 & 31 & 32 & 33 & 34 & 35 & 36 \\
\hline $\begin{array}{c}\text { Electrical } \\
\text { angle }\end{array}$ & 0 & 20 & 40 & 60 & 80 & 100 & 120 & 140 & 160 & 180 & 200 & 220 & 240 & 260 & 280 & 300 & 320 & 340 \\
\hline Conductor & + & + & + & + & + & + & + & + & + & - & - & - & - & - & - & - & - & - \\
\hline $\begin{array}{l}\text { Phase } \\
\text { current }\end{array}$ & $\mathrm{a}$ & b & $\mathrm{c}$ & $\mathrm{d}$ & $\mathrm{e}$ & f & g & $\mathrm{h}$ & $\mathrm{i}$ & $-\mathrm{a}$ & $-b$ & $-\mathrm{c}$ & $-\mathrm{d}$ & $-\mathrm{e}$ & $-f$ & $-\mathrm{g}$ & $-\mathrm{h}$ & $-\mathrm{i}$ \\
\hline Poles & \multicolumn{9}{|c|}{$\mathbf{N}$} & \multicolumn{9}{|c|}{$\mathbf{S}$} \\
\hline
\end{tabular}

Table 4. Conductor current for 6 phases with 6 poles

\begin{tabular}{|c|c|c|c|c|c|c|c|c|c|c|c|c|c|c|c|c|c|c|}
\hline Slot No. & 1 & 2 & 3 & 4 & 5 & 6 & 7 & 8 & 9 & 10 & 11 & 12 & 13 & 14 & 15 & 16 & 17 & 18 \\
\hline $\begin{array}{c}\text { Electrical } \\
\text { angle }\end{array}$ & 0 & 30 & 60 & 90 & 120 & 150 & 180 & 210 & 240 & 270 & 300 & 330 & 0 & 30 & 60 & 90 & 120 & 150 \\
\hline Conductor & + & + & + & + & + & + & - & - & - & - & - & - & + & + & + & + & + & + \\
\hline $\begin{array}{l}\text { Phase } \\
\text { current }\end{array}$ & $\mathrm{a}$ & $\mathrm{b}$ & $\mathrm{c}$ & d & $\mathrm{e}$ & $f$ & $-\mathrm{a}$ & $-b$ & $-\mathrm{c}$ & $-\mathrm{d}$ & $-\mathrm{e}$ & $-f$ & $\mathrm{a}$ & $\mathrm{b}$ & $\mathrm{c}$ & d & $\mathrm{e}$ & $\mathrm{f}$ \\
\hline Poles & \multicolumn{6}{|c|}{$\mathbf{N}$} & \multicolumn{6}{|c|}{$\mathbf{S}$} & \multicolumn{6}{|c|}{$\mathbf{N}$} \\
\hline Slot No. & 19 & 20 & 21 & 22 & 23 & 24 & 25 & 26 & 27 & 28 & 29 & 30 & 31 & 32 & 33 & 34 & 35 & 36 \\
\hline $\begin{array}{c}\text { Electrical } \\
\text { angle }\end{array}$ & 180 & 210 & 240 & 270 & 300 & 330 & 0 & 30 & 60 & 90 & 120 & 150 & 180 & 210 & 240 & 270 & 300 & 330 \\
\hline Conductor & - & - & - & - & - & - & + & + & + & + & + & + & - & - & - & - & - & - \\
\hline $\begin{array}{l}\text { Phase } \\
\text { current }\end{array}$ & $-\mathrm{a}$ & $-b$ & $-\mathrm{c}$ & $-\mathrm{d}$ & $-\mathrm{e}$ & $-f$ & $\mathrm{a}$ & $\mathrm{b}$ & $\mathrm{c}$ & d & $\mathrm{e}$ & $\mathrm{f}$ & $-\mathrm{a}$ & $-b$ & $-\mathrm{c}$ & $-d$ & $-\mathrm{e}$ & $-\mathrm{f}$ \\
\hline Poles & \multicolumn{6}{|c|}{$\mathbf{S}$} & \multicolumn{6}{|c|}{$\mathbf{N}$} & \multicolumn{6}{|c|}{$\mathbf{S}$} \\
\hline
\end{tabular}


Table 5. Conductor current for 3 phases with 12 poles

\begin{tabular}{|c|c|c|c|c|c|c|c|c|c|c|c|c|c|c|c|c|c|c|}
\hline Slot No. & 1 & 2 & 3 & 4 & 5 & 6 & 7 & 8 & 9 & 10 & 11 & 12 & 13 & 14 & 15 & 16 & 17 & 18 \\
\hline $\begin{array}{c}\text { Electrical } \\
\text { angle }\end{array}$ & 0 & 60 & 120 & 180 & 240 & 300 & 0 & 60 & 120 & 180 & 240 & 300 & 0 & 60 & 120 & 180 & 240 & 300 \\
\hline Conductor & + & + & + & - & - & - & + & + & + & - & - & - & + & + & + & - & - & - \\
\hline $\begin{array}{l}\text { Phase } \\
\text { current }\end{array}$ & $\mathrm{a}$ & $\mathrm{b}$ & c & $-a$ & $-b$ & $-\mathrm{c}$ & $\mathrm{a}$ & $\mathrm{b}$ & $\mathrm{c}$ & $-\mathrm{a}$ & $-b$ & $-c$ & $\mathrm{a}$ & $\mathrm{b}$ & $\mathrm{c}$ & $-\mathrm{a}$ & $-b$ & $-c$ \\
\hline Poles & \multicolumn{3}{|c|}{$\mathbf{N}$} & \multicolumn{3}{|c|}{$\mathbf{S}$} & \multicolumn{3}{|c|}{$\mathbf{N}$} & \multicolumn{3}{|c|}{$\mathbf{S}$} & \multicolumn{3}{|c|}{$\mathbf{N}$} & \multicolumn{3}{|c|}{$\mathbf{S}$} \\
\hline Slot No. & 19 & 20 & 21 & 22 & 23 & 24 & 25 & 26 & 27 & 28 & 29 & 30 & 31 & 32 & 33 & 34 & 35 & 36 \\
\hline $\begin{array}{c}\text { Electrical } \\
\text { angle }\end{array}$ & 0 & 60 & 120 & 180 & 240 & 300 & 0 & 60 & 120 & 180 & 240 & 300 & 0 & 60 & 120 & 180 & 240 & 300 \\
\hline Conductor & + & + & + & - & - & - & + & + & + & - & - & - & + & + & + & - & - & - \\
\hline $\begin{array}{l}\text { Phase } \\
\text { current }\end{array}$ & a & $\mathrm{b}$ & c & $-\mathrm{a}$ & $-\mathrm{b}$ & $-c$ & $\mathrm{a}$ & $\mathrm{b}$ & $\mathrm{c}$ & $-\mathrm{a}$ & $-b$ & $-c$ & $\mathrm{a}$ & $\mathrm{b}$ & c & $-\mathrm{a}$ & $-b$ & $-c$ \\
\hline Poles & \multicolumn{3}{|c|}{$\mathbf{N}$} & & \multicolumn{3}{|c|}{$\mathbf{N}$} & \multicolumn{3}{|c|}{$\mathbf{S}$} & \multicolumn{3}{|c|}{$\mathbf{N}$} & \multicolumn{3}{|c|}{ 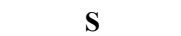 } \\
\hline
\end{tabular}

Table 6. Conductor current for 2 phases with 18 poles

\begin{tabular}{|c|c|c|c|c|c|c|c|c|c|c|c|c|c|c|c|c|c|c|}
\hline Slot No. & 1 & 2 & 3 & 4 & 5 & 6 & 7 & 8 & 9 & 10 & 11 & 12 & 13 & 14 & 15 & 16 & 17 & 18 \\
\hline $\begin{array}{c}\text { Electrical } \\
\text { angle }\end{array}$ & 0 & 90 & 180 & 270 & 0 & 90 & 180 & 270 & 0 & 90 & 180 & 270 & 0 & 90 & 180 & 270 & 0 & 90 \\
\hline Conductor & + & + & - & - & + & + & - & - & + & + & - & - & + & + & - & - & + & + \\
\hline $\begin{array}{l}\text { Phase } \\
\text { current }\end{array}$ & $\mathrm{a}$ & b & $-\mathrm{a}$ & $-b$ & $\mathrm{a}$ & b & $-\mathrm{a}$ & $-b$ & $\mathrm{a}$ & $\mathrm{b}$ & $-\mathrm{a}$ & $-b$ & $\mathrm{a}$ & $\mathrm{b}$ & $-\mathrm{a}$ & $-b$ & $\mathrm{a}$ & b \\
\hline Poles & \multicolumn{2}{|c|}{$\mathbf{N}$} & \multicolumn{2}{|c|}{ S } & \multicolumn{2}{|c|}{$\mathbf{N}$} & \multicolumn{2}{|c|}{ S } & \multicolumn{2}{|c|}{$\mathbf{N}$} & \multicolumn{2}{|c|}{$\mathrm{S}$} & \multicolumn{2}{|c|}{$\mathbf{N}$} & \multicolumn{2}{|c|}{ S } & \multicolumn{2}{|c|}{$\mathbf{N}$} \\
\hline Slot No. & 19 & 20 & 21 & 22 & 23 & 24 & 25 & 26 & 27 & 28 & 29 & 30 & 31 & 32 & 33 & 34 & 35 & 36 \\
\hline $\begin{array}{c}\text { Electrical } \\
\text { angle }\end{array}$ & 180 & 270 & 0 & 90 & 180 & 270 & 0 & 90 & 180 & 270 & 0 & 90 & 180 & 270 & 0 & 90 & 180 & 270 \\
\hline Conductor & - & - & + & + & - & - & + & + & - & - & + & + & - & - & + & + & - & - \\
\hline $\begin{array}{l}\text { Phase } \\
\text { current }\end{array}$ & $-\mathrm{a}$ & $-b$ & $\mathrm{a}$ & $\mathrm{b}$ & $-\mathrm{a}$ & $-b$ & $\mathrm{a}$ & $\mathrm{b}$ & $-\mathrm{a}$ & $-b$ & a & b & $-\mathrm{a}$ & $-b$ & $\mathrm{a}$ & b & $-\mathrm{a}$ & $-b$ \\
\hline Poles & \multicolumn{2}{|c|}{$\mathbf{S}$} & \multicolumn{2}{|c|}{$\mathbf{N}$} & \multicolumn{2}{|c|}{$\mathbf{S}$} & \multicolumn{2}{|c|}{$\mathbf{N}$} & \multicolumn{2}{|c|}{$\mathbf{S}$} & \multicolumn{2}{|c|}{$\mathrm{T}$} & \multicolumn{2}{|c|}{ S } & \multicolumn{2}{|c|}{$\mathbf{N}$} & \multicolumn{2}{|c|}{5} \\
\hline
\end{tabular}

\section{Simulation results by FEM}

Two-dimensional (2D) transient finite element method (FEM) is employed to compute the performances of the novel multiphase IM, the advantages of the transient FEM is that the realistic conditions of lamination geometries, core materials, and winding connections are all considered collectively and faithfully. As shown in Table 1, a multiphase squirrel cage induction motor (IM) drive with five speed ratios using PPM is used as a typical example. The performance of the novel multiphase IM working in five different pole pairs is analysed respectively by FEM.

\subsection{Flux density distribution}

In the novel multiphase IM, when stator conductors are excited by multi-phase symmetrical sinusoidal AC currents, the rotating magnetic field will be generated in the machine, and 
the back EMF voltages will be induced in multiphase stator conductors. If the mechanical load is coupled with the motor shaft, then the motor will output mechanical power and it is running in loaded condition. In the finite element analysis, we have directly calculated the flux distribution and the flux density distribution for the five pole phase combinations. Fig. 3 shows the flux distributions of the novel multiphase IM operating in five different pole pairs in this paper.

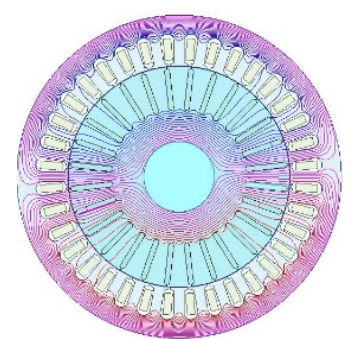

a) $2 p=2$

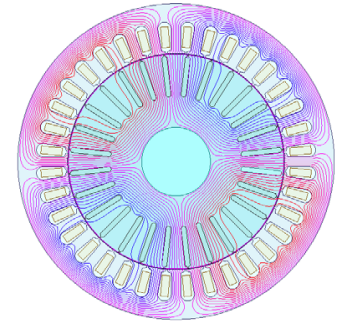

b) $2 p=4$

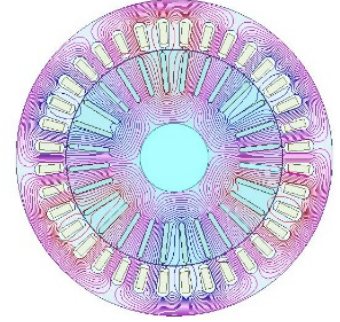

c) $2 p=6$

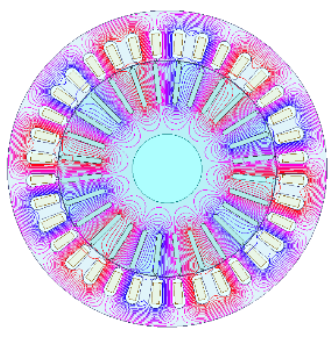

d) $2 p=12$

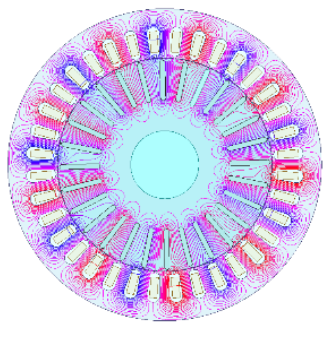

e) $2 p=18$

Fig. 3. Flux line distribution for five different pole phase operation

Flux density distributions of the novel multiphase IM for five pole phase combinations which is running in loaded operation are shown in Fig. 4. From Fig. 4, it is clearly to be found that with the increase of the pole pairs of the novel multiphase IM at rated operation situation, the flux density in stator tooth is saturation, and it in stator yoke is very low, not saturation. The reason is that when the pole pairs of the novel multiphase IM increase at rated operation situation, flux lines going through stator teeth will increase, while stator yoke on the contrary. The maximum value of flux density for the five pole phase operations is approximately 1.8-2.0T.

The air gap flux density of five pole phase combinations and the harmonic contents of the air gap flux density are shown in Fig. 5 and Fig. 6, respectively. From Fig. 5, we can find that the amplitude of air gap flux density is about 1.4T. Hence, air gap flux density at different pole phase situations isn't over saturated. In Fig. 6, the contents and values of the higher harmonics of air gap flux density in five pole phase conditions are small enough not to influence performance of the novel IM. So the novel multiphase IM has a better electromagnetic performance for each pole phase operation. This is possible to achieve the torque performance of the novel IM working in five different pole pairs. 


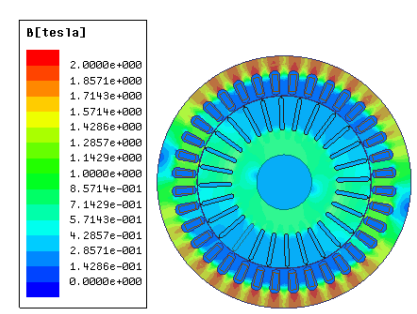

a) $2 p=2$
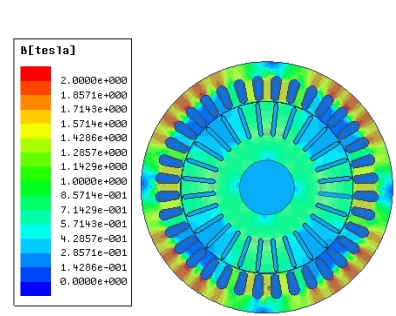

b) $2 p=4$
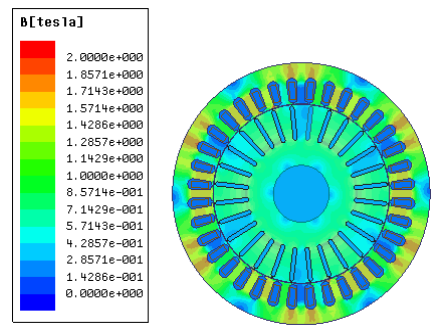

c) $2 p=6$
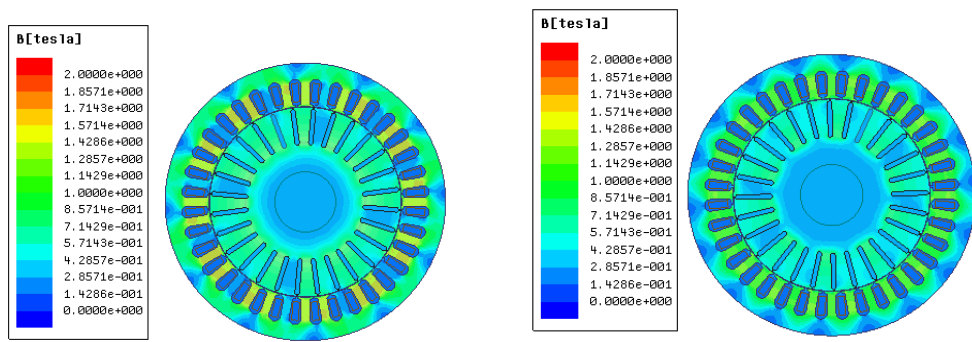

d) $2 p=12$

e) $2 p=18$

Fig. 4. Flux density distribution for five different pole phase operation

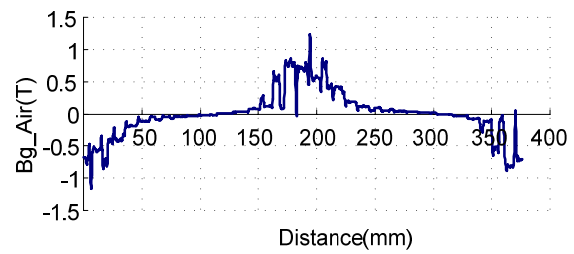

a) $2 p=2$

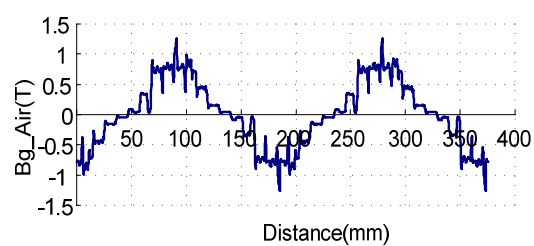

b) $2 p=4$

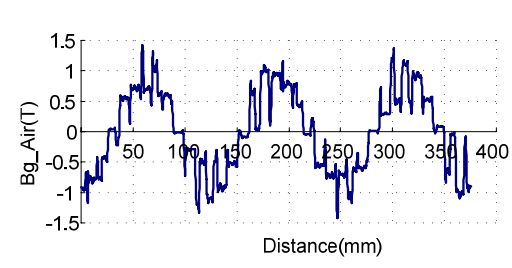

c) $2 p=6$

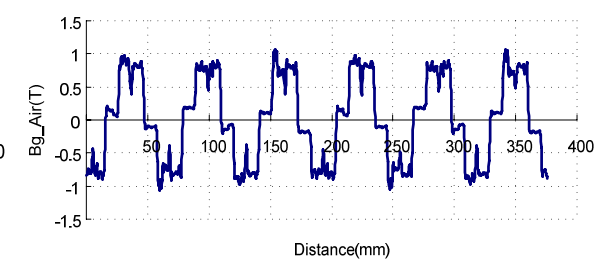

d) $2 p=12$

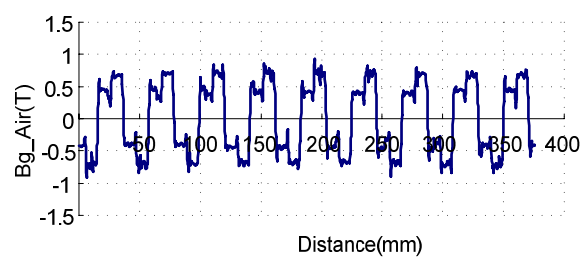

e) $2 p=18$

Fig. 5. Air gap flux density of five pole phase operations 


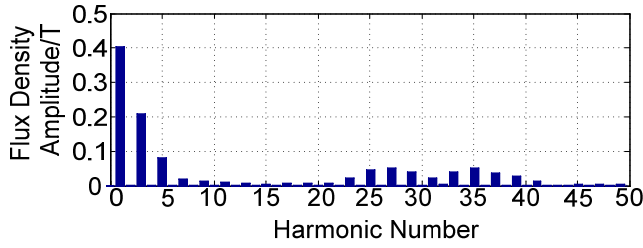

a) $2 p=2$

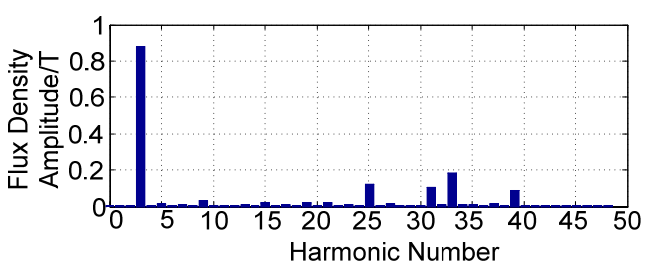

c) $2 p=6$

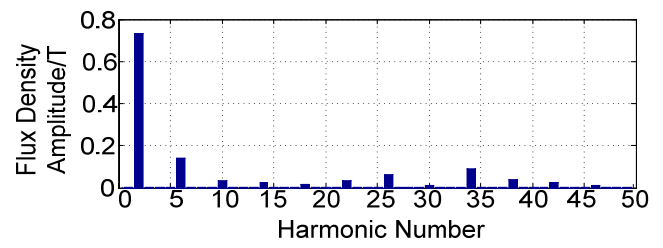

b) $2 p=4$

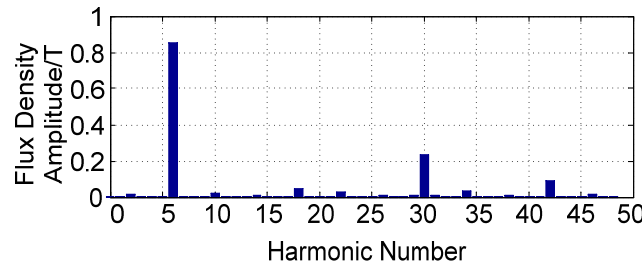

d) $2 p=12$

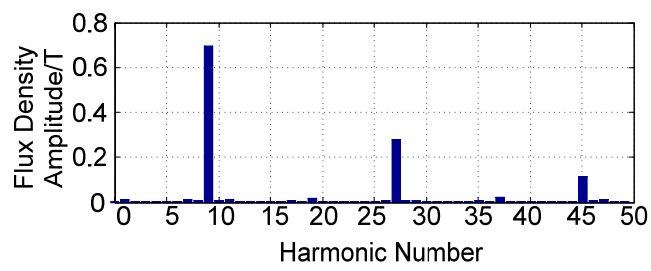

e) $2 p=18$

Fig. 6. Air gap flux density harmonic analysis of five pole phase operations

\subsection{Torque speed characteristics}

When the induction motor is running at loaded condition, there are three kinds of torque acting on the rotor, the electromagnetic torque $T e$, the load torque $T 2$, and the no-load torque $T 0$. When the induction motor operates at a normal state, the electro-magnetic torque is the driving torque; the load torque and no-load torque are the braking torque.

The TS-FEM is used to compute the torque performances when the five types IMs running at full-load condition and the slip $s=0.013$. The torque versus time curves of five pole phase combinations are shown in Fig. 7. The output torque value of the five different pole phase IM running at full-load condition and the slip $s=0.013$ are $4.4 \mathrm{Nm}$ for 18 phase 2 pole IM, $7.5 \mathrm{Nm}$ for 9 phase 4 pole IM, $18.1 \mathrm{Nm}$ for 6 phase 6 pole IM, $4 \mathrm{Nm}$ for 3 phase 12 pole IM and $2 \mathrm{Nm}$ for 2 phase 18 pole IM. Therefore, we can find that the 6 phase 6 pole IM has the largest torque, and the 2 phase 18 pole IM has the smallest one.

In IM, the torque is also varied with the motor speed, and the torque versus speed curve is called mechanical characteristic, which is denoted by $n=f(T e)$, when the voltage, the frequency and the motor parameters are constant. The mechanical characteristics of five types of IM running at full load condition are shown in Fig. 8 . The scale of $x$-coordinate in Fig. 8 is denoted with the natural logarithm of speed $n$.

In Fig. 8, the maximum torque value of the five different pole phase IM are $9.1 \mathrm{Nm}$ for 18 phase 2 pole IM, $19.2 \mathrm{Nm}$ for 9 phase 4 pole IM, $22.7 \mathrm{Nm}$ for 6 phase 6 pole IM, $13.6 \mathrm{Nm}$ for 
3 phase 12 pole IM and $7 \mathrm{Nm}$ for 2 phase 18 pole IM. And the torque of 6 phase 6 pole IM is the largest one, that of 2 phase 18 pole IM is the smallest one.

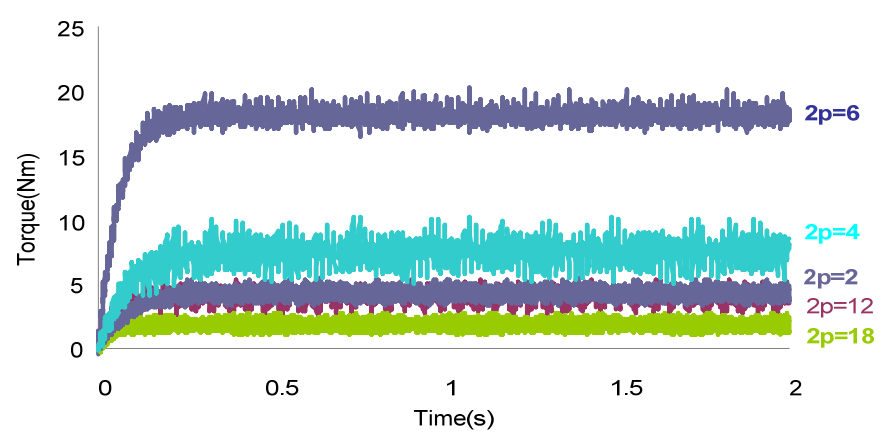

Fig. 7. Torque curves of five different pole phase operations at rated situation

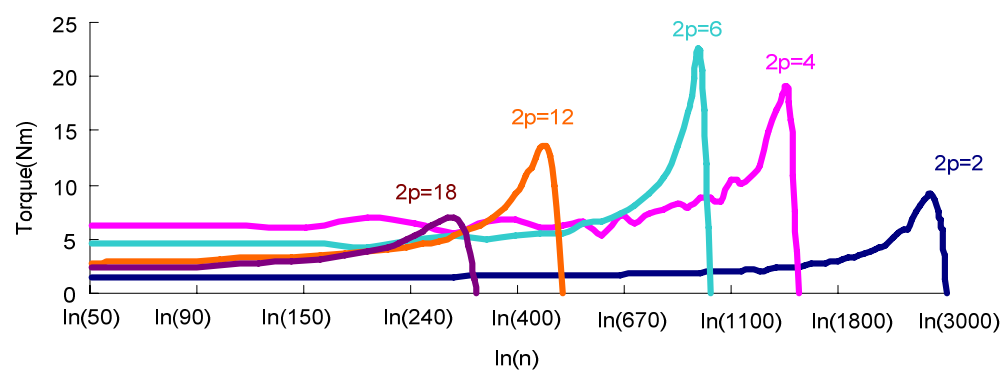

Fig. 8. Torque curves of five different pole phase operations

The most important is that the constant power speed regulation can be realized when the IMs running with 6 pole, 4 pole and 2 pole conditions, and the speed range of the five different pole phase IM is expanded, which is important for the vehicle driving system applications.

\subsection{Energy efficiency}

The efficiency of the induction motor is the ratio between the output active power and the input active power. It is usually expressed in percentage:

$$
\eta=\frac{P_{2}}{P_{1}} \times 100 \%,
$$

where $P_{1}$ is the input active power, $P_{2}$ is the output active power. The output active power $P_{2}=T_{2} \Omega$, and $\Omega$ is the rotor mechanical angular speed. The input active power $P_{1}=P_{2}+p_{\text {loss }}$, and $p_{\text {loss }}$ is the total losses of the motor. And the total losses consist of stator copper losses $\left(p_{c u}\right)$, core losses $\left(p_{F e}\right)$, mechanical losses $\left(p_{f w}\right)$, stray losses $\left(p_{s}\right)$ and rotor copper losses $\left(p_{A l}\right)$, namely $p_{\text {loss }}=p_{c u}+p_{F e}+p_{f w}+p_{s}+p_{A l}$.

Time-stepping FEM is employed to analyse the transient performance of the motor and the core losses calculation in the frequency domain is based on the following equation [11]: 


$$
P_{\text {core }}=P_{\text {hys }}+P_{\text {eddy }}+P_{\text {add }},
$$

where $P_{h y s}$ is the hysteresis loss, $P_{\text {eddy }}$ is the eddy current loss, and $P_{a d d}$ is the additional loss (or excess loss).

The three types of loss in the time domain can be computed by

$$
\begin{gathered}
P_{h y s}=\frac{l_{z}}{T} \int_{0}^{T}\left(\int_{\Omega} \boldsymbol{H}_{i r r} \cdot \frac{\mathrm{d} \boldsymbol{B}}{\mathrm{d} t} \mathrm{~d} \Omega\right) \mathrm{d} t=\frac{l_{z}}{T} \int_{0}^{T}\left(\int_{\Omega}\left(H_{x-i r r} \cdot \frac{\mathrm{d} B_{x}}{\mathrm{~d} t}+H_{y-i r r} \cdot \frac{\mathrm{d} B_{y}}{\mathrm{~d} t}\right) \mathrm{d} \Omega\right) \mathrm{d} t, \\
P_{\text {eddy }}=\frac{l_{z}}{2 \pi^{2}} \iint_{\Omega} k_{\text {eddy }}\left[\left(\frac{\mathrm{d} B_{x}}{\mathrm{~d} t}\right)^{2}+\left(\frac{\mathrm{d} B_{y}}{\mathrm{~d} t}\right)^{2}\right] \mathrm{d} \Omega, \\
P_{\text {add }}=\frac{l_{z}}{C_{\text {add }}} \iint_{\Omega} k_{\text {add }}\left[\left(\frac{\mathrm{d} B_{x}}{\mathrm{~d} t}\right)^{2}+\left(\frac{\mathrm{d} B_{y}}{\mathrm{~d} t}\right)^{2}\right]^{\frac{3}{4}} \mathrm{~d} \Omega,
\end{gathered}
$$

where $l_{z}$ is the axial length of the iron core and $T$ is the period of the applied voltage. $\boldsymbol{H}_{i r}$ is the irreversible component of the magnetic field $\boldsymbol{H}$ and it can be determined according to the iron loss curves by the assumption that the trace of $\boldsymbol{H}_{i r r}$ is an elliptical loop. $H_{x-i r r}$ and $H_{y \text {-irr }}$ are the $x$ and $y$ components of the magnetic field vector $\boldsymbol{H}$ respectively. $\boldsymbol{B}$ is the flux density vector of the magnetic field, $B_{x}$ and $B_{y}$ are the $x$ and $y$ components of the flux density vector $\boldsymbol{B}$ respectively. The coefficient $K_{\text {eddy }}$ and $K_{\text {add }}$ can be calculated according to the core loss curves using linear regression algorithm. According to [11], $C_{\text {add }}=8.763363$.

In the analysis, the phase resistor of the stator winding in the effective region (excluding the end winding) is:

$$
r=\frac{1}{3} N_{s} N_{c} \frac{\rho L}{S_{c}}=\frac{1}{3} N_{s} N_{c}^{2} \frac{\rho L}{S_{s}},
$$

then the total copper loss is:

$$
p_{C u}=3 I^{2} r=I^{2} N_{s} N_{c}^{2} \frac{\rho L}{S_{s}}=I^{2} N_{s}^{2} N_{c}^{2} \frac{\rho L}{S_{w}} .
$$

$S_{w}$ is the cross-sectional area of all the slots and it will be the same in all the motors being studied for consistent comparison. $N_{s} N_{c}$ is the total number of conductors in all the slots of each motor, and $N_{s} N_{c}=1$. From Eq. (7) it can be seen that for the five operations, owing to the stator and the stator windings, and the rated stator current $(5.45 \mathrm{~A})$ are all the same, then the ampere-conductors $I N_{s} N_{c}$ are the same and the stator copper loss are the same.

Computing the core losses of the motor running in five conditions by the time-stepping FEM, is based on Eqs. (2)-(5). The computed core loss curves versus time at different operation of the motor are shown in Fig. 9. 


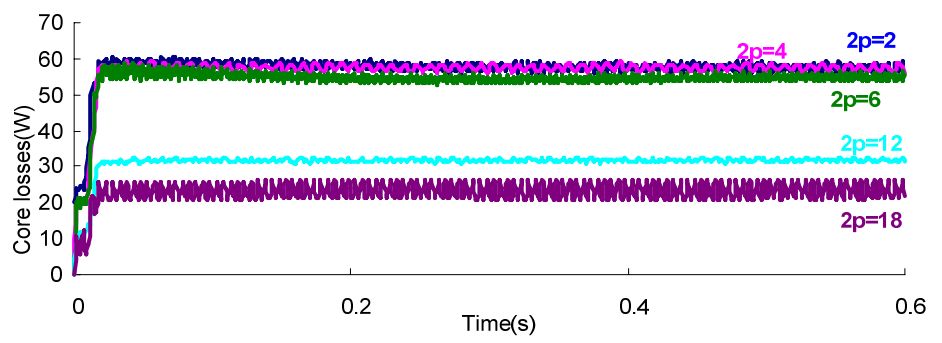

Fig. 9. Core losses versus time curve of five different pole phase operations

From Fig. 9, the average core losses of the five different pole phase operations is $57.6 \mathrm{~W}$ for 2 pole operation, $58.0 \mathrm{~W}$ for 4 pole operation, $54.9 \mathrm{~W}$ for 6 pole operation, $31.9 \mathrm{~W}$ for 12 pole operation, $23.4 \mathrm{~W}$ for 18 pole operation respectively. Due to stator windings and stator currents in five different pole phase operations are the same, and then the copper losses will be the same. The other losses are estimated according to the output active power.

Table 7. Efficiencies of five pole phase operations

\begin{tabular}{l|c|c|c|c|c}
\hline & $\begin{array}{c}\mathbf{1 8 p h a s e} \\
\text { 2 pole }\end{array}$ & $\begin{array}{c}\mathbf{9} \text { phase } \\
\text { 4 pole }\end{array}$ & $\begin{array}{c}\mathbf{6} \text { phase } \\
\mathbf{6} \text { phase }\end{array}$ & $\begin{array}{c}\text { 3 phase } \\
\mathbf{1 2} \text { pole }\end{array}$ & $\begin{array}{c}\mathbf{2} \text { phase } \\
\mathbf{1 8} \text { pole }\end{array}$ \\
\hline Output power $P_{2}(\mathrm{~W})$ & 1366 & 1159 & 1834 & 203.3 & 69 \\
\hline Stator copper losses $p_{c u}(\mathrm{~W})$ & 2.4 & 2.4 & 2.4 & 2.4 & 2.4 \\
\hline Core losses $p_{F e}(\mathrm{~W})$ & 57.6 & 58 & 54.9 & 31.9 & 22 \\
\hline Mechanical losses $p_{f w}(\mathrm{~W})$ & 84 & 21 & 9.38 & 2.34 & 1 \\
\hline Stray losses $p_{s}(\mathrm{~W})$ & 25.32 & 22.14 & 35.28 & 3.06 & 1.08 \\
\hline Rotor copper losses $p_{A l}(\mathrm{~W})$ & 40.58 & 33.3 & 40.52 & 4.8 & 1.07 \\
\hline Efficiency $(\%)$ & 86.7 & 89.4 & 92.1 & 81.3 & 70 \\
\hline
\end{tabular}

Table 7 shows the total losses and the efficiency values of the motor at five pole phase operations. The efficiency of 6 phase 6 pole IM can achieve $92.1 \%$, The efficiencies of three types of IM ( 2 phase 18 pole, 9 phase 4 pole and 3 phase 12 pole) are all above $80 \%$.

\section{Conclusions}

In this paper, five pole-phase combination types of a multiphase induction motor (IM) which has 36 stator slots and 36 stator conductors are presented and compared quantitatively by using time-stepping finite element method (TS-FEM). The following conclusion can be drawn.

1) The novel multiphase IM can be run in five different pole-phase combinations with best utilization of copper. The phase-angle of stator current can be changed to realize the switch-over among five pole phase operations. When the proposed IM operates among 6 phase 6 pole, 9 phase 4 pole and 18 phase 2 pole, constant power speed regulation can be realized and the speed range is expanded. 
2) When the novel multiphase IM operates with five different pole pairs, the energy efficiency of the four different pole phase operations is above $80 \%$. Based on the above mentioned advantages, the proposed IM shows great potential for the use in electrical vehicle driving applications.

\section{Acknowledgements}

This work was supported by the National Natural Science Foundation of China (No. 51377008).

\section{References}

[1] Kelly J.W., A novel control scheme for a pole-changing induction motor drive, $\mathrm{PhD}$ Thesis, Michigan State University (2007).

[2] Gopakumar K., Sathiakumar S., Biswas S.K., Vithayathil J., Modified current source inverter fed induction motor drive with reduced torque pulsations, IEE proceedings 131(4): 159-164 (1984).

[3] Pavithran K.N., Parimelalagan R., Krishnamurthy M.R., Studies on inverter-fed five-phase induction motor drive, IEEE Trans. Power Electron. 3(2): 224-235 (1988).

[4] Rawcliffe G.H., Burbidge R.F., A 2:1 pole-changing induction motor of improved performance, IEE proceedings 104(18):457-460 (1957).

[5] Osama M., Lipo T.A., Modeling and analysis of a wide-speed-range induction motor drive based on electronic pole changing, IEEE Transactions on Industry Applications 33(5): 1177-1184 (1997).

[6] Rajaraman K.C., Design of phase-change two-speed windings for induction motors, using pole-amplitude modulation techniques, IEE proceedings 131(5): 232-233 (1984).

[7] RawclitIe G.H., Fong W., Clock diagrams and pole amplitude modulation, PROC. IEE 118(5): 675-680 (1971).

[8] Rawcliffe G.H., Jayawant B.Y., The development of a new 3:1 pole-changing motor, Proc. IEEE 103(9): 306-316 (1956).

[9] Sun D.S., Ge B.M., Bi D.Q., Winding design for pole-phase modulation of induction machines, Energy Conversion Congress and Exposition, Delft 278-283 (2010).

[10] Umesh B.S., Sivakumar K., 15 phase induction motor drive with 1:3:5 speed ratios using pole phase modulation, The 2014 International Power Electronics Conference, Hiroshima, pp. 14001404 (2014).

[11] Lin D., Zhou P., Fu W.N., Stanton S., Cendes Z.J., A dynamic core loss model for soft ferromagnetic and power ferrite materials in transient finite element analysis, IEEE Trans. Magn. 40(2): 1318-1321 (2004). 